\title{
Challenges in Dam Safety and Extreme Rainfall Estimation in Relation to Sri Lanka
}

\author{
S. S. Wickramasuriya and W. C. D. K. Fernando
}

\begin{abstract}
Ensuring the safety of our dams in a changing global climate is of paramount importance to Sri Lanka. The devastating floods of January - February 2011 caused an enormous Rs. 66 billion in damages which included a massive Rs. 13 billion loss in the rice crop alone. A million people were rendered homeless and 62 lives were lost. Many major reservoirs spilled, while a few medium sized and several hundred minor tanks breached. Batticaloa experienced record rainfall, while Senanayake Samudra the country's largest reservoir was spilling after 16 years. Sri Lanka has over 300 large and medium sized dams. These could experience overtopping due to extreme rainfall, the consequences of which would be disastrous. Hence there is a necessity to regularly assess the adequacy of present spillways using detailed hydrological studies which include the estimation of probable maximum precipitation (PMP) and probable maximum flood (PMF). The estimation of extreme rainfall is a highly controversial issue but nonetheless critical in relation to dam safety. While overestimation of extreme values would be uneconomical, underestimation could be disastrous. Thus arriving at realistic estimates while being aware of inherent risk and uncertainty, is a challenge in hydrologic design. The paper presents 24-hour point PMP values for several meteorological stations in Sri Lanka, using the hydro-meteorological and statistical procedures. The work which is based on extensive studies done by the authors during the past several years, and published both locally and internationally, could be effectively used in current and future dam safety studies.
\end{abstract}

Keywords: Dam Safety, Probable Maximum Precipitation, Extreme rainfall

\section{Introduction}

Irrigation dams are a national treasure, and it is crucial that their safety and operational efficiency be ensured. About $90 \%$ of the developed water resources of Sri Lanka are utilized by irrigated agriculture that accounts for approximately $80 \%$ of rice production and appropriate management of this precious resource is vital for food security (Imbulana, et. al. [20]).

Following the devastating floods of December 1957 which destroyed a large number of major and minor irrigation systems, the eminent irrigation engineer Mr. Arumugam in his Presidential Address to the Ceylon Association for the Advancement of Science stated, "The December 1957 flood is now an event of the past. It has been designated 'Catastrophic Flood', 'once in a two hundred year flood', 'once in a hundred year flood', whatever that may be - there is nothing to prevent the occurrence of another flood of equal severity or even more anytime" (Arumugam, [8]). Over half a century later, the recent floods during December 2010 - February 2011, which affected nearly two million people particularly in the eastern and north central provinces, together with other flood disasters in the region call for serious reflection.

Over a 30 day period commencing from $15^{\text {th }}$ December, Batticaloa experienced its average annual rainfall and a maximum daily rainfall of $312.2 \mathrm{~mm}$, which was the third highest on record. Also during the period 1871-2011, while there are only four occurrences of daily rainfall exceeding $300 \mathrm{~mm}$ at Batticaloa, three of these occurred during the last 50 years (1962-2011). In addition to many major reservoirs, the Senanayake Samudra is reported to have spilled after 16 long years. It was only in November 2010, that Colombo experienced its second largest 24 hour rainfall of $440.2 \mathrm{~mm}$ which flooded vast extents of urban areas, including the surroundings of the parliament and rendered nearly 200,000 people homeless (DMC, [12]). Within the period 1992-2010, Colombo experienced four large daily rainfall values which included the highest two on record.

Eng. (Prof.) S.S. Wickramasuriya, B.Sc. Eng. (Hons) (Moratuwa), PhD. (UNSW), C. Eng., MIE(Sri Lanka), Associate Professor, Department of Civil Engineering, University of Moratuwa, Sri Lanka.

Eng. (Dr.) (Mrs.) W. C. D. K. Fernando, B.Sc. Eng. (Hons) (Moratuwa), M. Eng (Moratuwa), PhD. (Moratuwa), AMIE(Sri Lanka), Snr. Lecturer, Department of Civil Engineering, General Sir John Kotelawala Defence University, Sri Lanka. 
Are these indications that hydrological extremes could be increasing in severity and frequency?

\section{Hydrological Extremes: Severity and Frequency}

Several countries such as Pakistan, Brazil, Philippines, and Australia have recently experienced severe flooding with disastrous consequences. Sri Lanka too has not escaped nature's fury and some disasters are thought to be linked to the La Nina phenomenon (Wickramasuriya \& Fernando, [31]). Certain others have experienced diverse forms of climatic extremities, such as the severe snow storm of February 2011 which covered nearly a third of the US (Wisniewski, [34]) and the record breaking killer tornadoes of April 2011.

According to the IPCC [22], "Generally, numbers of heavy daily precipitation events that lead to flooding have increased, but not everywhere. Tropical storm and hurricane frequencies vary considerably from year to year, but evidence suggests substantial increases in intensity and duration since the 1970s.......". In a recent award winning paper, a group of Japanese researchers highlighted and mapped areas where flood and drought risks can change with a changing climate. The topic of the paper is very timely. In many areas, water-related extremes have already become more frequent and/or more severe in the changing climate, and projections are indicating further increase of frequency and severity. However it should be noted that such projections could also have a substantial degree of uncertainty (IAHS, [21]).

The World Rivers Review of September 2010 states "The catastrophic flooding in Pakistan provides a terrifying warning of how global warming is changing the hydrological cycle. Almost every month seems to bring unprecedented rainstorms and floods somewhere across the world, and their severity and frequency seems to be rapidly worsening. These floods pose a major threat to the world's dams, and to the many millions of people who live below them." Referring to China, "The huge Three Gorges Dam had some dangerous days during China's recent flood disaster. The dam experienced the biggest surge of water since it began operating four years ago, and its reservoir rose $4 \mathrm{~m}(13 \mathrm{ft})$ in just a day. ...... In recent years, Chinese officials have downgraded the dam's flood-control capacity from "able to withstand the worst flood in 10,000 years" in 2003, to 1000 years in 2007, and to 100 years in 2008." (Pottinger, [24]).

Thus available evidence strongly suggests that in some regions, hydrological extremes are increasing in severity and frequency. Coupled with ever growing concerns about the possible impact of global climate change, a critical issue that arises in relation to Sri Lanka is that of dam safety and the adequacy of spillways against extreme rainfalls and floods. Suppose the adequacy of spillways of major dams is to be assessed, how does one proceed to estimate or ascertain a realistic upper limit of extreme rainfall for the exercise? An overestimation would have adverse economic implications, while an underestimation will impact safety and have disastrous consequences. For embankment dams, the percentage of global dam failures due to overtopping, which includes inadequate spillway capacity as the main factor is 49\% (Meghella \& Eusebio, [5]). Spillways of major dams where failure would result in the loss of life, are designed to safely pass the Probable Maximum Flood (PMF), which in turn requires an estimate of Probable Maximum Precipitation (PMP).

The objective of this paper is to address this challenging and vital issue of estimating PMP at several stations in Sri Lanka, in the light of current research, with due consideration given to extreme rainfall events of recent times and the past.

\section{Extreme Rainfall and Probable Maximum Precipitation (PMP) - Concepts and Controversies}

The estimation of extreme rainfall and PMP is not only a challenging task in hydrologic design, but also a highly controversial one. Basically there are two separate approaches adopted by researchers and these are the deterministic and probabilistic methods of estimating extreme values. The former is based on the understanding of the underlying processes, while the latter is rooted in the laws of probability and statistics. Over 40 years ago, the world renowned hydrologist Yevjevich [33] in a landmark paper titled, "Misconceptions in Hydrology and Their Consequences" stated, "Persistent use of the concept of maximum 
precipitation and maximum probable precipitation, for which there is no physical proof, has discouraged research into the structure and probability of extreme events, and may have led to an unwarranted sense of security concerning flood control works". Thus the necessity of incorporating a probabilistic or stochastic approach in the estimation of extremes was emphasized. Some have even advocated that the concept of PMP should have been abandoned (Benson, [9]).

On the other hand, speaking on the use of probability distributions and large scale extrapolations to estimate return periods based on the concept of stationarity, another world famous hydrologist Klemes [23] in "Tall Tales about Tails of Distributions" states, "......the increased mathematization of hydrological frequency analysis over the past 50 years has not increased the validity of estimates of the frequencies of high extremes and thus has not improved our ability to assess the safety of structures whose design characteristics are based on them. The distribution models used now, though disguised in serious mathematical garb, are no more, and quite likely less valid for estimating the probabilities of rare events than were the extensions "by eye" of duration curves employed 50 years ago.....As a result, the bulk of frequency analysis theory, with all its exalted rigor and polish, is spurious, not to say dangerous. It creates an illusion of knowledge where none exists - and illusion of knowledge can do more harm than awareness of ignorance". A more detailed discussion on this topic is given by Sellers [6].

Thus it is seen that both schools of thought have had their critics. However it is encouraging to note that there are still other researchers who have advocated a unified approach to modelling, by integrating concepts which apparently differ widely (Vogel, [28]; Fernando, [3]). Amidst various uncertainties, the concept of PMP continues to be used extensively both from a research perspective and in the design of spillways of major dams to estimate the PMF so as to minimize the risk of failure and the loss of life (Fernando and Wickramasuriya, [13]; Casas, et al. [10]; Desa \& Rakecha, [11]; Rezecova et al. [25]).

It is thus seen that the estimation of PMP is a current topic which is both challenging and controversial, with immense practical significance especially in the context of dam safety. The methodologies developed and presented herein can be effectively applied in design office practice (Fernando \& Wickramasuriya, [16]).

\section{Dam Safety - Flood History and PMP Studies in Sri Lanka}

The floods of 1957 caused serious damage to 35 major irrigation systems and 1300 village works (Arumugam, [1]). Several major dams such as Huruluwewa, Kalawewa and Nachchaduwa breached in this catastrophic event. Following this, a program to increase the discharge capacities of spillways was undertaken. However, the original and subsequent design information is not available for the older dams and hence a proper assessment of flood safety was required. Under the Dam Safety and Reservoir Conservation Program (DS\&RCP) launched in 2003, the adequacy of spillways was assessed under PMP/PMF conditions for 32 selected dams, together with many other aspects that were also investigated. Pioneering work done by the principal author in this regard is presented in Wickramasuriya et al. [30] and Wickramasuriya et al. [32].

Reflecting on the 1957 floods, Arumugam [8] states "The deluge from such depressions and the impact of large quantities of water amassed and released suddenly into an already full reservoir, creates problems of storage, accommodation and safe exit that are not easily solved. Widening of spillways, provision of high level emergency spills and the incorporation of steel lifting gated spillways do alleviate, but no water conservation work is safe without a suitable breaching section for emergency release." It should be noted that in the recent January/February 2011 floods, in order to control the flood levels at the Nachchaduwa dam which was also under a major left bank sluice repair, the high level spill/breaching section had to be opened to provide additional capacity to discharge the flood waters. Parakrama Samudra, where extensive repairs had to be done following the November 1978 cyclone, according to newspaper reports had been breached during the 1957 floods.

The aspect of breaching sections raises another vital and related issue, that of reservations and encroachment. Following the breach of the Kantalai Tank Bund, the report of the commission of inquiry states, "Another matter 
that was stressed was that each of these tanks should have its own reservation area around it. Officers of the Irrigation Department complained that these reservations are very frequently encroached on, that it is harmful to the bund and inspections and maintenance are made more difficult because of these encroachments. ........... around each tank there should be a tank reservation area, reserves must be strictly maintained and encroachments should not be allowed on any condition. ......... also a retired Senior Deputy Director, has taken the trouble to prepare comprehensive guidelines for the preparation of Standing Orders for dams and reservoirs. This team would do well to study these guidelines when preparing their scheme of inspection and maintenance." (Sessional Paper No. 7, [26]).

In the context of dam safety it is very important to consider the impact caused by some historic floods. Valuable information regarding rainfall amounts and intensities, flood levels and discharges can be extracted from such events and used as predictive tools in design. Some notable historic flood events have been, 1907, 1978 (Batticaloa); 1947 (Ratnapura); 1957, 2011 (Eastern, North Central Provinces); 2003 (Ratnapura, Kalutara, Southern Province); 1992, 2010 (Colombo). Interestingly it has been suggested how cyclonic storms could probably have caused the collapse of ancient engineering works (Wickramasuriya, [29]).

The understanding of various geophysical processes and theories underlying extreme events is still a matter of continuous investigation. The idea of complete safety is unrealistic when dealing with design floods and there is always the inherent element of risk and uncertainty. Risk analysis accepts events of any magnitude as being possible, although as the magnitude increases the probability of exceedence decreases. In this regard the flood disaster on Kariba dam on river Zambezi is a classic example well worth noting (Gaskill, [4]; Wickramasuriya et al. [32]). Thus in addition to the theoretical aspects comprising data analysis; a detailed study of flood history, future projections, field conditions, inundation issues and economic aspects should be considered in a final assessment of dam safety and spillway adequacy. In case of emergencies due to unprecedented events, mechanisms to rapidly evacuate the affected to safer locations, while ensuring proper channels of communication between relevant authorities should be in place.
Initial work on PMP estimation done by Wickramasuriya et al. (2004) [32] showed the distinct possibility of the World Meteorological Organization (WMO, [7]) statistical procedure being potentially suitable for dam safety studies in Sri Lanka, with the availability of comprehensive data on rainfall. Thereafter detailed studies on PMP estimation considering 18 stations in Sri Lanka covering several climatic zones and 22 foreign stations have been done by Fernando [3], Fernando and Wickramasuriya ([13], [14], [15], [16], [17]).

\section{Sri Lanka - Weather Patterns, Stations and Recent Floods}

Sri Lanka is a tropical island of $65000 \mathrm{~km}^{2}$ area located in the Indian Ocean, near the southern tip of India and lies between $5^{0} 55^{\prime} \mathrm{N}$ and $9^{0} 50^{\prime}$ $\mathrm{N}$ latitudes and $79^{\circ} 42^{\prime} \mathrm{E}$ and $81^{\circ} 53^{\prime} \mathrm{E}$ longitudes. The climate of Sri Lanka is characterized by the Asian monsoon system and during the year, the country experiences the southwest monsoon (SWM) (May September) and northeast monsoon (NEM) (December - February). These periods are interspersed by two inter-monsoonal periods, March-April (IM1) and October -November (IM2) and these seasons bring convectional rains. Figure 1 shows the selected rainfall stations and Figure 2 indicates the resulting bimodal distribution of mean monthly rainfall at these stations, over the period 1961-1990. According to Figure 3, nearly 70\% of cyclones and depressions over the country occur during the period October - December (Thambyahpillay, [27]). The average annual rainfall for the country is $1860 \mathrm{~mm}$ and it varies spatially between $950 \mathrm{~mm}$ and $5500 \mathrm{~mm}$ over the island (CEA, [2]).

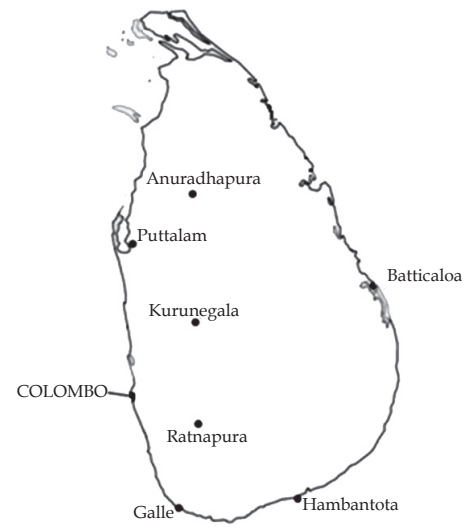

Figure 1 - Locations of the selected rainfall stations in Sri Lanka (Department of Meteorology) 
A period of heavy rainfall was observed commencing from the latter part of November 2010 in the Eastern and North Central provinces. During December 2010, rainfall at Batticaloa was $805.1 \mathrm{~mm}$, which is double the mean monthly rainfall in December based on the 1961-1990 period. In January 2011, Batticaloa received $1368.9 \mathrm{~mm}$ of rainfall which exceeded the previous January record of 1365 $\mathrm{mm}$ after 98 years (Wickramasuriya \& Fernando, [31]). The cumulative daily rainfall for the total period of 105 days considered from the beginning of November shows the severity of this rainfall event (Figure 4) where Batticaloa experienced over double the rainfall of Anuradhapura. During January, an alarming situation arose with Batticaloa experiencing $967.8 \mathrm{~mm}$ of intense rainfall over five days, which is approximately $60 \%$ of its mean annual rainfall. This was followed by Anuradhapura and Batticaloa receiving approximately an additional $360 \mathrm{~mm}$ and $500 \mathrm{~mm}$ respectively during the first week of February, further aggravating the disastrous flood situation. The January - February floods which occurred in two successive spells, resulted in the loss of 62 lives, a million people were rendered homeless and several hundred minor tanks breached.

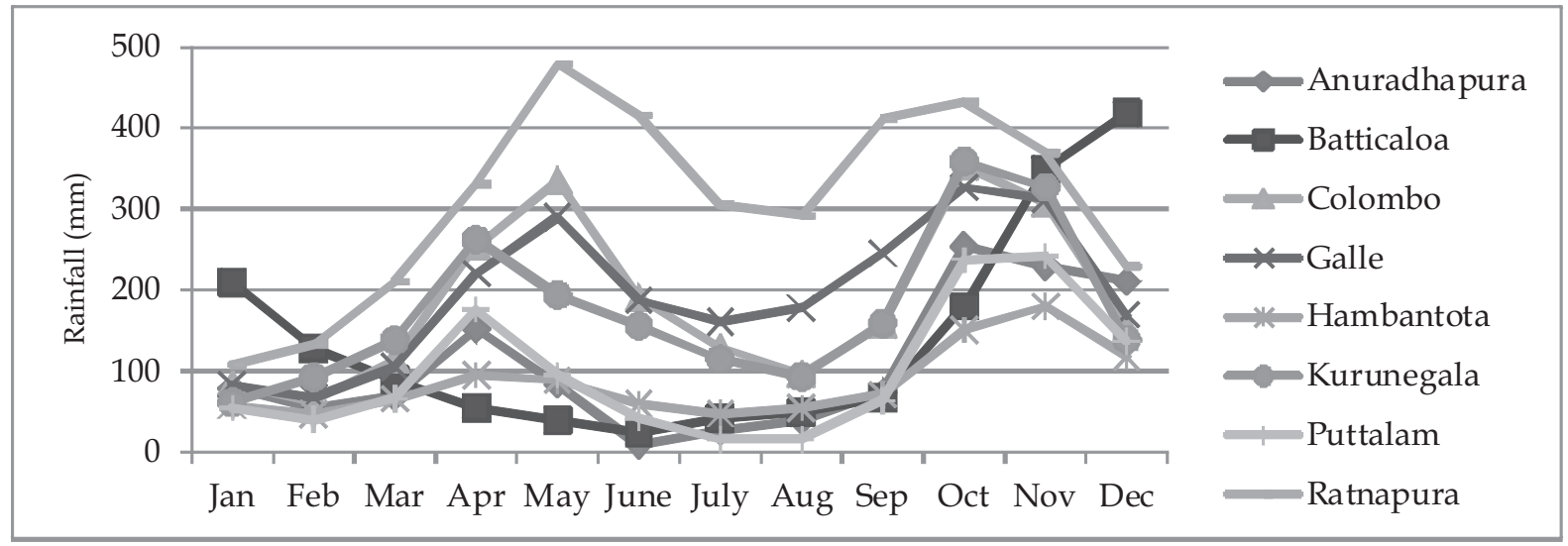

Figure 2 - Mean monthly rainfall at selected stations during 1961 - 1990 (Department of Meteorology, Sri Lanka)

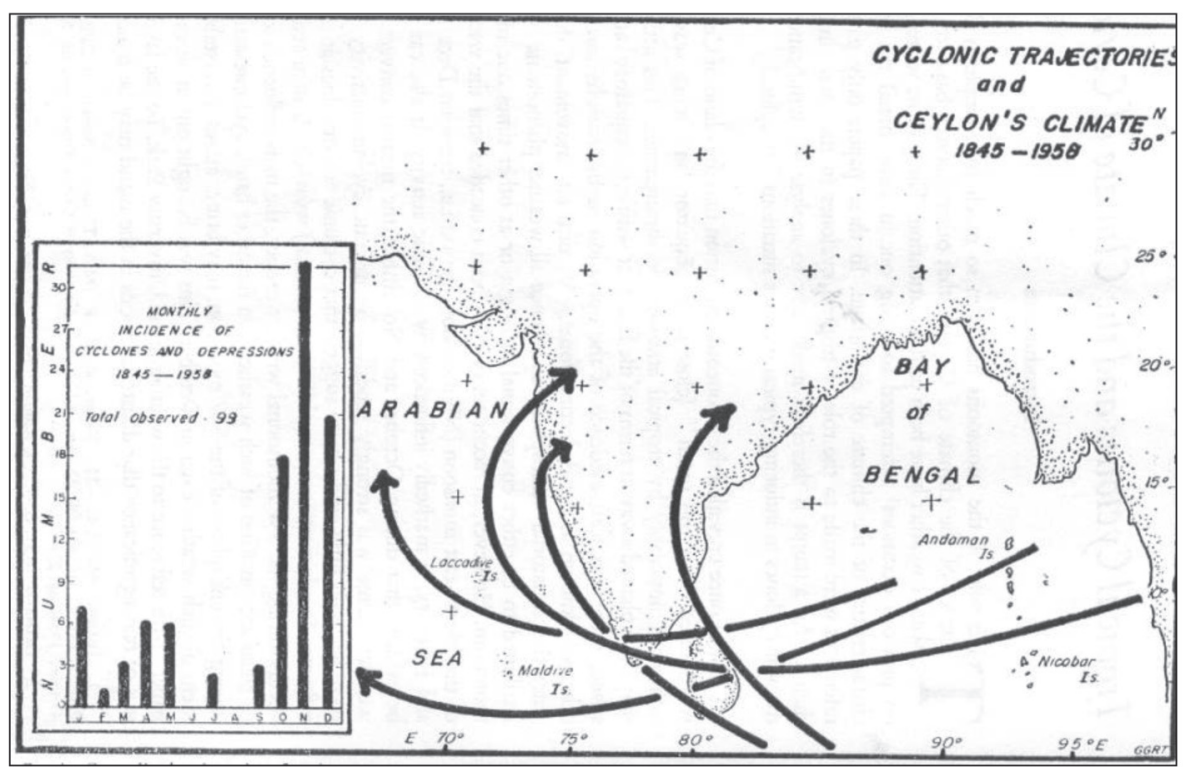

Figure 3 - Cyclonic trajectories during 1845 - 1958 (Thambyahpillay, [27]) 


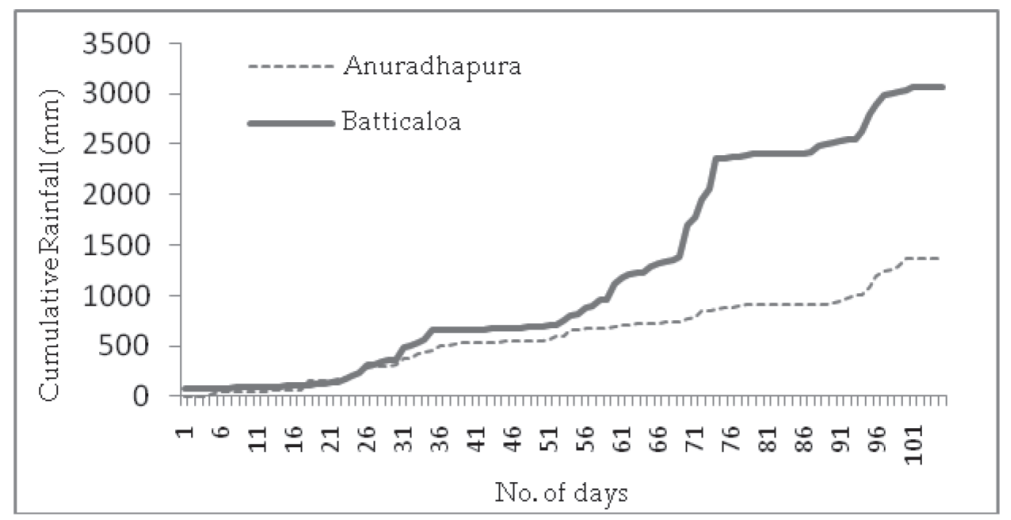

Figure 4 - Cumulative daily rainfall (Nov. 2010 - Feb 2011)

\section{Methodology - Estimation of PMP}

Prior to estimating PMP, it is of interest to know some of the highest point rainfall values recorded in Sri Lanka. The greatest daily rainfall recorded for the island is $805.6 \mathrm{~mm}$ at Nedunkerni on 16.12.1897. This is followed by 792mm (Vavuniya, 19.12.1911), $755.9 \mathrm{~mm}$ (Rasagala, 17.05.1940) and 730mm (Deniyaya, 17.05.2003).

PMP is defined as "the theoretically greatest depth of precipitation for a given duration, that is physically possible over a given size storm area, at a particular geographical location, at a certain time of the year with no allowance made for long-term climatic trends" (WMO [7]). Inherent in the concept of PMP is the fundamental idea of 'climatologic potential'. Initially, annual maximum daily rainfall data from the selected rainfall stations were subjected to a variety of parametric and nonparametric tests and were found to satisfy the criteria of absence of trends, independence and homogeneity (Fernando, [3]).

Two basic methodologies as recommended by the WMO have been adopted for the estimation of PMP. In Hershfield's statistical method, annual maximum daily rainfalls have been used from the period 1900 to 2011 and the technique is clearly explained in Hershfield [18, 19] and WMO [7]. In the hydro-meteorological procedure, data prior to 1950 could not be considered due to the non-availability of dew point temperatures and wind speed.

\subsection{Statistical Method}

It should be noted that in developing the methodology, Hershfield considered daily rainfall data from 2600 stations of which about $90 \%$ were from the United States.

The procedure is based on the general frequency equation,

$\mathrm{X}_{\mathrm{T}}=\bar{X}+\mathrm{KS}$

where $X_{T}$ is the rainfall for return period $T$;

$\bar{X}$ and $\mathrm{S}$ are the mean and standard deviation respectively of a series of annual maxima and $\mathrm{K}$ is a frequency factor. Replacing $X_{T}$ by PMP, and making certain adjustments based on the maximum observed event, the sample size and fixed observational time intervals, the required PMP value for the station can be easily computed. Although the value of $\mathrm{K}$ was found to be in the order of 15 , some researchers have found that significant reductions in $\mathrm{K}$ values had to be incorporated for certain countries (Desa \& Rakecha, [11]). Hence K values should be estimated at the outset for the country or region, prior to applying the methodology.

According to the Manual for Estimation of Probable Maximum Precipitation of the World Meteorological Organization, "Statistical procedures for estimating PMP, may be used whenever sufficient precipitation data are available and are particularly useful for making quick estimates or where other meteorological data, such as dew point and wind records are lacking. The procedure described below is not the only one, but it has received the widest acceptance. It is used mostly for making quick estimates for watersheds of no more than about $1000 \mathrm{~km}^{2}$, but has been used for much larger areas. Its convenience lies in that it requires considerably less time to apply than does the meteorological or traditional approach and that one does not have to be a meteorologist to use it..."[WMO, 7]. Here lies the attractiveness of the statistical procedure, thus making it a valuable tool in hydrological design practice, 
enabling engineers to make relatively quick estimates of PMP (Wickramasuriya et al. [32]).

\subsection{Frequency factor $(K)$}

Based on detailed investigations done by Fernando [3], true frequency factors for Sri Lanka, are shown in Figure 5 and an enveloping curve was developed. This shows close agreement with Hershfield $\mathrm{K}$ values, with some minor alterations in the context of Sri Lanka.

\subsection{Statistical PMP - Equal sample size}

In this exercise, for each station five 50-year samples have been analysed and the lowest and highest PMP values are shown in Figure 7.

The difference between the maximum and minimum values of estimated PMP gives an indication of the change in extreme rainfall embedded in the sample.

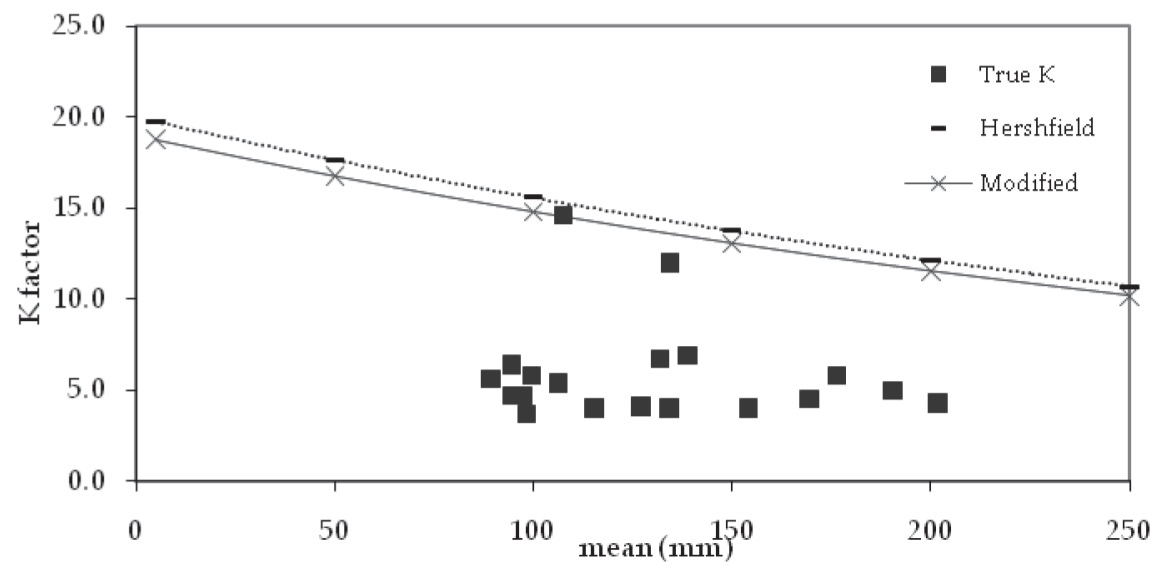

Figure 5 - Enveloping curve - Frequency factors for Sri Lanka

\subsection{Statistical PMP - Increasing sample size}

PMP values were estimated by increasing sample sizes in steps of 10 years for a period of 110 years. This enables one to study the effect of sample size on PMP (Figure 6).
For most of the stations, the difference between the maximum and minimum PMP values is less than $150 \mathrm{~mm}$, which once again demonstrates that the effect on PMP is minimal.

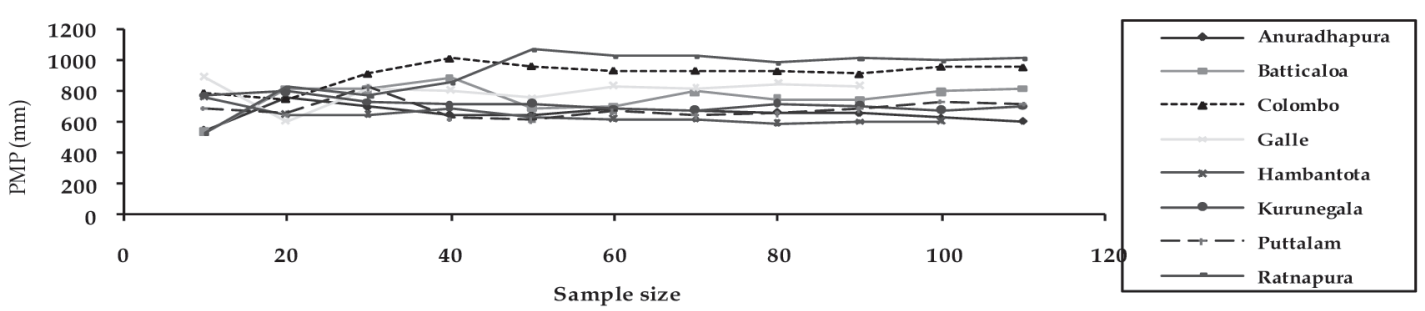

Figure 6 - The variation of PMP with increasing sample size

An abrupt change in the pattern of PMP can be seen due to the occurrence of an extreme rainfall when the sample size is relatively small. However as sample size is increased, it is observed that all stations except Batticaloa, yield remarkably stable values of PMP when the sample size is 50 years or more. Thus, in general with a large sample, the effect of an extreme value on the estimated PMP is marginal.
However, close attention is required with data that show a high degree of variability, due to the presence of more extreme values. This was the case in Batticaloa, where one 50-year sample (1962-2011) included three rainfall extremes which were larger than $300 \mathrm{~mm}$. This resulted in a $30 \%$ increase in standard deviation when compared with an average sample. Thus, the estimated PMP from this sample increased substantially. 


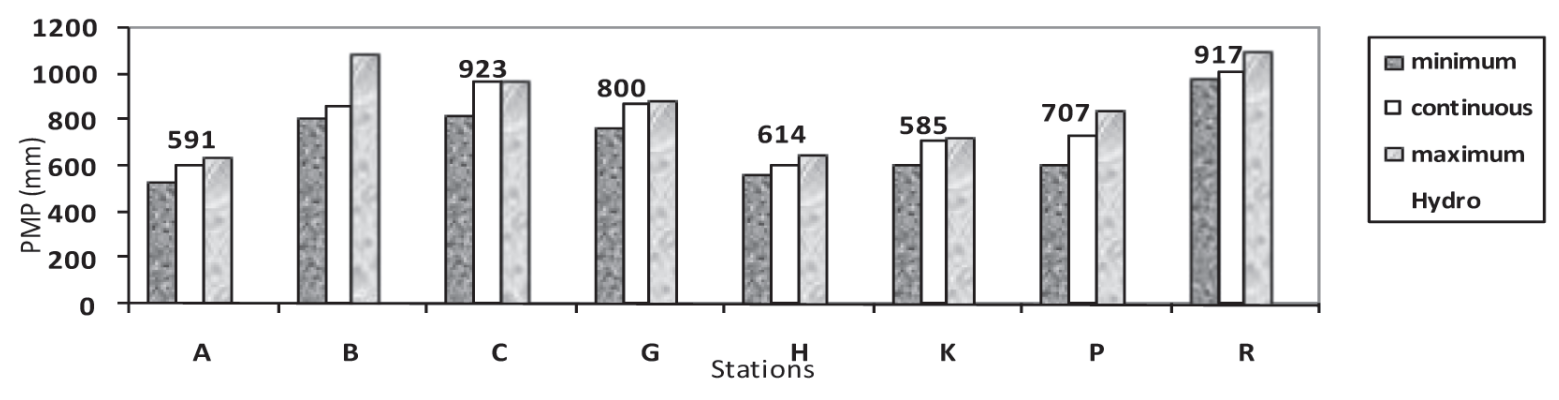

A - Anuradhapura, B - Batticaloa, C - Colombo, G - Galle, H - Hambantota, K - Kurunegala, P - Puttalam, R - Ratnapura

Hydro-meteorological values are shown in the figure.

Figure 7 - Comparison of statistical and hydro-meteorological PMP values

It is important to note that sample variance has a significant impact on the estimated PMP.

\subsection{Statistical PMP - A continuous record}

PMP values were also estimated by considering the whole data series and are also shown in Figure 7. These lie between the maximum and minimum values at all stations.

\subsection{Hydro-meteorological PMP}

Storm maximization which is a deterministic method, is used to increase the observed precipitation data, to get maximum moisture inflow theoretically possible, at the site either "in-situ" or by "transposition". Since there is an extensive rainfall network in Sri Lanka, this study is limited to in-situ storm maximization. Two important factors in this approach are moisture maximization factor and wind maximization factor.

The 24-hour point PMP values for seven meteorological stations (except Batticaloa) of Sri Lanka have been derived using the hydrometeorological method (Figure 7) (Fernando \& Wickramasuriya, [13]). The study considered three different scenarios for storm maximization. It was shown that S2 and S3 are probable scenarios, where S2 considers maximum moisture and a corresponding wind adjustment factor, while S3 represents maximum moisture only. Furthermore, it was shown that precipitation efficiency, wind maximization factor and return period of the PMP are three key elements in deciding the appropriate scenario between S2 and S3. Return periods were estimated using the Generalized Extreme Value (GEV) distribution with cumulative distribution function, $\mathrm{F}(\mathrm{x})=\exp \left\{-(1-\mathrm{k}(\underline{\mathrm{x}-\mu}))^{1 / \mathrm{k}}\right\}$

$\sigma$

where $\mu, \sigma$ and $\mathrm{k}$ are referred to as the location, scale and shape parameters respectively, which has been used extensively worldwide.

\section{Results and Discussion}

The results of 24-hour point PMP using hydrometeorological and statistical methods for selected stations from various climatic zones are shown in Table 1.

Having compared S2 and S3 scenarios, the selected hydro-meteorological PMP results are highlighted in Table 1. The statistical PMP results in Table 1 are based on data updated to include the severe storms at Batticaloa in 2011 and Colombo in 2010.

An appropriate enveloping curve showing the relationship between the frequency factor $\mathrm{K}$ and mean of annual maximum daily rainfall series has been developed (Figure 5). Results show that $K$ values for Sri Lanka closely 
Table 1- Estimated PMP values

\begin{tabular}{|l|c|c|c|c|c|}
\hline \multirow{2}{*}{ Station } & $\begin{array}{c}\text { Highest } \\
\text { observed daily } \\
\text { rainfall (mm) }\end{array}$ & $\begin{array}{c}\text { Hydro-meteorological } \\
\text { PMP (mm) }\end{array}$ & $\begin{array}{c}\text { Statistical PMP } \\
(\mathrm{mm})\end{array}$ & $\begin{array}{c}\text { Stat PMP } \\
\text { /highest } \\
\text { observed }\end{array}$ \\
\cline { 2 - 4 } Anuradhapura & 219.7 & 685 & 591 & 605 & 2.8 \\
Batticaloa & 330.7 & -1 & -1 & 857 & 2.6 \\
Colombo & 493.7 & $\mathbf{9 2 3}$ & 769 & 959 & 1.9 \\
Galle & 282.6 & $\mathbf{8 0 0}$ & 438 & 863 & 3.1 \\
Hambantota & 296.9 & $\mathbf{6 1 4}$ & 484 & 600 & 2.0 \\
Kurunegala & 249.4 & $585^{2}$ & 353 & 707 & 2.8 \\
Puttalam & 275.7 & 707 & 426 & 724 & 2.6 \\
Ratnapura & 394.4 & $\mathbf{9 1 7}$ & 518 & 1008 & 2.6 \\
\hline
\end{tabular}

${ }^{1}$ Dew point temperatures are not available

2 Inadequate wind records

resemble those specified in the WMO manual, although this cannot be generalized to all countries.

The statistical method yields almost identical results to the hydro-meteorological method at six out of seven stations where the percentage difference in results is less than $10 \%$. Thus, the statistical approach can be used as a dependable and efficient method in design office practice, when long records of annual maximum daily rainfall data are available. In contrast, the hydro-meteorological procedure is found to be tedious and time consuming when data on dew points and wind speeds have to be extracted manually. Nevertheless, the hydrometeorological procedure can be most useful in verification of statistical estimates of PMP.

Sri Lanka experiences depressions and cyclones which are often associated with heavy rainfall occurring over the period October to January. Hence the importance of incorporating wind adjustment in PMP estimation, although the global practice has been to usually disregard this aspect. The apparent low values of hydrometeorological PMPs in comparison to the statistical results at Kurunegala and Ratnapura could be attributed at least in part to the lack of wind records at these locations. At Anuradhapura, scenario S3 is selected since the storm was of high efficiency and there was no necessity to incorporate wind maximization (S2).

A preliminary estimate of 24-hour point PMP could be in the order of 2.0-3.0 times the maximum observed daily rainfall. However, this aspect deserves further investigation, when the observed maxima approach PMP values.

Generally as sample size increases, the PMP values tend to converge to a stable value.
However in Batticaloa, there were three severe storms (exceeding $300 \mathrm{~mm}$ of daily rainfall) in the last 50 year period which had a significant impact on the statistical PMP estimated from this sample. This aspect too deserves further study from a hydro-meteorological perspective, especially in the context of climate change.

\section{Conclusions}

Ensuring the safety of our dams in a changing global climate is a major challenge that engineers and other professionals have to face in the coming years. The estimation of Probable Maximum Precipitation (PMP) is a critical factor in dam safety for assessing the adequacy of spillways of major dams. PMP values for 24hour duration for several Sri Lankan stations from different climatic zones have been estimated. The estimation of Probable Maximum Precipitation (PMP) is a highly controversial issue but nonetheless an essential parameter required for the critical and challenging task of evaluating spillway adequacy.

Since Sri Lanka has an extensive computerized database of rainfall, the statistical method is an efficient and dependable method for use in design office practice. It is always prudent to ascertain the validity of such results by using the hydro-meteorological method. While global practice has been usually to disregard wind maximization when using the hydrometeorological approach, it is a necessary parameter to be considered in addition to moisture maximization, in relation to Sri Lanka which experiences cyclones and depressions. The PMP values are remarkably similar in both techniques for most of the stations. The hydrometeorological procedure, although more time consuming, can be very useful if statistical 
estimates of PMP require further verification. The methodologies incorporating various improvements have been published locally and internationally. These can be effectively utilized in current and future dam safety studies and for developing PMP maps for Sri Lanka. Several countries have already developed PMP maps for various durations and it is strongly recommended that Sri Lanka too should expedite this exercise. Further studies are underway to develop simple relationships to make quick preliminary estimates of PMP.

In addition to estimating the likely upper limits of rainfall and associated runoff, other important factors such as flood history, inundation, field conditions, anticipated changes in environment and economic issues also have an important bearing on the issue of dam safety. Hence factors such as breaching sections, encroachment, electro-mechanical aspects and hydrological forecasting are integral issues in dam safety. Ensuring emergency measures for rapid evacuation of affected populations and ensuring effective communication among relevant authorities are other factors that can assist in disaster mitigation in case of unprecedented events.

With the ever increasing concern of climatic and other environmental changes, PMP estimates should be regularly updated, especially considering the recent rainfall events such as in Batticaloa and Colombo. It is strongly recommended that hydrological data pertaining to precipitation, infiltration, runoff and other catchment characteristics be monitored spatially and temporally at a few representative dam sites. The use of current technologies such as Remote Sensing and GIS could greatly enhance this process. Information so gathered from the field, would facilitate improved hydrological analyses in future dam safety studies.

\section{References}

1. Arumugam, S., Water Resources of Ceylon, Water Resources Board, Sri Lanka, 1969.

2. Central Environmental Authority (CEA), Environmental atlas of Sri Lanka, CEA, Sri Lanka, 2005.

3. Fernando W. C. D. K., An Integrated Approach for Estimating Probable Maximum Precipitation Incorporating the Concept of Threshold, Unpublished $\mathrm{PhD}$ thesis, University of Moratuwa, Sri Lanka, 2011.

4. Gaskill, G., Kariba Dam: Master of the Zambezi, The Reader's Digest, 1959.

5. Meghella, M. and Eusebio, M., "A Risk Assessment Tool to Effectively Support Decision
Makers to Prioritize Maintenance, Repair and Upgrading of Dams", Dam Maintenance and Rehabilitation, Llanos, et. al. (Eds.), Swets and Zeitlinger, pp. 159-168, 2003.

6. Sellers, C. D. (Ed.) Common Sense and Other Heresies, Selected papers on Hydrology and Water Resources Engineering by Vit Klemes, Canadian Water Resources Association, Ontario, Canada, 2000.

7. World Meteorological Organization, (WMO), "Manual for Estimation of Probable Maximum Precipitation: Operational Hydrology", Rep.1, WMO no. 332 (2nd ed), Geneva, 1986.

8. Arumugam, S., "The Floods of December 1957 and their Impact on Water Conservation Works" Presidential Address, Section C, Ceylon Association for the Advancement of Science, 1960.

9. Benson, M. A., "Thoughts on the Design of Design Floods: Floods \& Droughts", Proceedings of the 2nd International Symposium on Hydrology, Water Resources Publications: Fort Collins, CO, USA; pp. 27-33, 1973.

10. Casas, M. C., Rodriguez, R., Prohom, M., Gazquez, A. and Redano, A., "Estimation of the Probable Maximum Precipitation in Barcelona (Spain)", International Journal of Climatology, DOI: 10.1002/joc.2149, 2010.

11. Desa, M. N. and Rakhecha, P. R., "Probable Maximum Precipitation for 24-h duration Over an Equatorial Region: Part 2-Johor, Malaysia", Atmospheric Research, Vol. 84, pp. 84-90, 2007.

12. Disaster Management Centre (DMC), Situation Report, 12 November as at 1800hrs, 2010.

13. Fernando, W. C. D. K. and Wickramasuriya, S. S., "The Hydro-Meteorological Estimation of Probable Maximum Precipitation under Varying Scenarios in Sri Lanka", International Journal of Climatology, Vol. 31, pp. 668-676, 2011.

14. Fernando, W. C. D. K. and Wickramasuriya, S. S., "Estimating Extreme Rainfall in Sri Lanka under Monsoonal and Cyclonic Environments", Exploring New Spheres for a better Future, Annual Symposium, 2009, General Sir John Kotelawala Defence University, p. 31, 2009.

15. Fernando, W. C. D. K. and Wickramasuriya, S. S. "A Statistical Approach for Estimating the Probable Maximum Precipitation in Sri Lanka", Proceedings of the International Statistics Conference, Applied Statistics Association of Sri Lanka, 2009.

16. Fernando, W. C. D. K. and Wickramasuriya, S. S., "Estimating Probable Maximum Precipitation - from Research to Design", Engineer, Institution of Engineers, Sri Lanka, Vol. 40(4), pp. 116-122, 2007.

17. Fernando, K. \& Wickramasuriya, S. S., "Some Issues in the Estimation of Probable Maximum Precipitation", Proceedings of International Conference on Sustainable Water Resources Management in the Changing Environment of the Monsoon Region, Sri Lanka, United Nations University: Japan, Vol. 1, pp. 153-165. 2004.

18. Hershfield, D. M., "Estimating the Probable Maximum Precipitation", Proc. Am. Soc. of Civil 
Engineers, J. Hydraulics Division, Vol. 87(9), pp. 99-106, 1961.

19. Hershfield, D. M., "Method for Estimating the Probable Maximum Precipitation", J. American Waterworks Association, Vol. 57(8), pp. 965-972, 1965.

20. Imbulana, U. S., Fraiture, C. de. and Makin, I., "Sustainable Management of Water Resources Utilized for Irrigated Agriculture in Sri Lanka", Proceedings of the Twelfth Congress of the Asia and Pacific Division of the IAHR, Vol. iv, Water Resources Development and Management, REMC, AIT, Thailand, pp. 1127-1136, 2000.

21. International Association of Hydrological Sciences (IAHS), IAHS Newsletter NL 95, December, 2009.

22. Intergovernmental Panel on Climate Change (IPCC), Climate change 2007: Working group I: The Physical Science Basis, IPCC Fourth Assessment Report, 2007.

23. Klemes, V., "Tall tales about tails of hydrological distributions", Journal of Hydrologic Engineering, ASCE, Vol. 5(3), pp. 227-231 (a) and pp. 232-239 (b), 2000.

24. Pottinger, L., "A Flood of Dam Safety Problems", International Rivers, September, 2010.

25. Rezacova, D., Pesice, P. and Sokol, Z., "An Estimation of the Probable Maximum Precipitation for River Basins in the Czech Republic, Atmospheric Research, Vol. 77, pp. 407421, 2005.

26. Sri Lanka Sessional Paper No VII - Report of the Findings of the Commission of Inquiry into the Breach of the Kantalai Tank Bund, Report of the Breach of the Kantalai Tank Bund, p. 60, 1987.

27. Thambyahpillay, G., "Tropical Cyclones and the Climate of Ceylon", University of Ceylon Review, Vol. XVII (3\&4), pp. 137-180, 1959.

28. Vogel, R. M., "Stochastic and Deterministic World Views", Journal of Water Resources Planning and Management, Vol. 125(6), November/December, pp. 311-313, 1999.

29. Wickramasuriya, A. T. G. A., "What Caused the Collapse of the Ancient Engineering Works"?, Island 17th and 19th Nov. 1990.

30. Wickramasuriya, S. S., Sutcliffe, J, Vanathy, I., and Wickramaratne, S., "Assessment of Adequacy of Spillways for Dam Safety and Reservoir Conservation in Sri Lanka", International Conference on Hydrology: Science and Practice for the 21st century, British Hydrological Society, London, 2004.

31. Wickramasuriya, S. S. and Fernando, W. C. D. K., "Reliable Estimates of Probable Maximum
Precipitation for Disaster Risk Reduction", Paper submitted to International Conference on Building Resilience, 2011.

32. Wickramasuriya, S. S., Vanathy, I., and Wickramaratne, S., "Some Hydrological Issues in the Assessment of Dam Safety", Annual Transactions of Institute of Engineers, Sri Lanka, Vol. 1(B), pp. 329-339, 2004.

33. Yevjevich, V., "Misconceptions in Hydrology and their Consequences", Water Resources Research, Vol. 4(2), pp. 225-232, 1968.

34. Wisniewski, M., Winter storm engulfs huge swath of U.S. Washington Post, (available online http:/ / www.washingtonpost.com/ [accessed on 09/02/2011]), 2011. 